\title{
Evaluation of Landslide Susceptibility Using Scientific Investigation and Quantitative Evaluation
}

\author{
Young-Karb Song, Jeongrim Oh, Young-Jin Son and MinSu Jung \\ National Disaster Management Institute, Republic of Korea \\ karb@korea.kr
}

\begin{abstract}
Landslide disasters in steep slopes in urban areas are increasing due to climate change. In Korea most of the steep-slope disasters are induced by typhoons and torrential rains in the Summer time, causing many casualties, property damages, and recovery costs. In order to response this disaster it is imperative to implement the scientific site investigation on potential slope areas and evaluate their vulnerability quantitatively. The efficient maintenance and management of steep slopes often require excessive professional resources and quantitative investigations. Therefore, it is important to develop a technology for the objective scientific site investigation and quantitative evaluation for steep slopes. In this study we proposed Evaluation system which evaluates the stability analysis of steep slopes and provides a vulnerability level.
\end{abstract}

Keywords: Landslide, Steep Slope, Stability analysis, Vulnerability

\section{Introduction}

Recently the frequency and impact of disasters due to the climate change have been increased and it is usual trend in Korea. The steep slope failures (landslide), which are the representative natural disasters in Korea, generate 22.8 casualties every year (NDMI, 2012). In order to response this disaster it is imperative to implement the scientific site investigation on potential slope areas and evaluate their vulnerability quantitatively. Studies on the investigation methodology and the device development, which are combined with the IT technology in the fields of investigation and management of steep slopes were carried out by Koo et al., (2007), Lee (2005), Jang et al., (2010), Park and Park (2011), and Shim et al., (2006). Most of them, however, have focused on the investigation for artificial slopes and studies on same issues for natural slopes such as vulnerability assessment, identification of the extent and impact due to the landslides are not fully satisfactory. In this study, therefore, a system which reducing time and workload compared to the existing methodologies by delineating analyzing, acquiring, and storing data, and evaluating vulnerability and collapse of natural as well as artificial slopes is developed.

\section{Slope Disasters in KOREA}

Over the last ten years human casualties by various natural disasters in Korea are reported every year and the number of deaths by steep-slope related disasters is also reported continuously (NDMS, 2012). Serious cased can be found during the typhoon and torrential rain events, i.e., Typhoon Rusa in 2002 and torrential rain in 2011. According to the statistics over the past ten years from 2002 to 2011, it is found that the number of deaths by various natural disasters is 689 and, among them, 228 deaths are due to steep-slope related disasters 
indicating that about $33 \%$ of human deaths by natural disasters is attributed to slope-stability related geological disasters in Korea. Table 1 shows the number of deaths by natural disasters, steep-slope disasters, and their relative ratios in Korea (NDMI, 2012).

Table 1. Death by natural and steep-slope related disasters in Korea over the past ten years

\begin{tabular}{c|c|c|c}
\hline Year & by Natural Disaster & by Slope-stability related Disaster & Ratio (\%) \\
\hline \hline Total & 689 & 228 & \multirow{2}{*}{33.1} \\
\hline Average & 68.9 & 22.8 & 29.3 \\
\hline 2002 & 270 & 79 & 25.0 \\
\hline 2003 & 148 & 37 & 21.4 \\
\hline 2004 & 14 & 3 & 21.2 \\
\hline 2005 & 52 & 11 & 35.5 \\
\hline 2006 & 62 & 22 & 17.4 \\
\hline 2007 & 23 & 4 & 50.0 \\
\hline 2008 & 16 & 8 & 50.0 \\
\hline 2009 & 12 & 6 & 7.0 \\
\hline 2010 & 14 & 1 & 73.1 \\
\hline 2011 & 78 & 57 & \\
\hline
\end{tabular}

\section{Development of Field Investigation System}

\subsection{Selecting HW/SW through site Investigation and Desktop Studies}

When steep slope-related disasters occur, various analyses have to be conducted to understand the causes and calculate the scope of damage. First of all, for desktop studies, topographic characteristics, history of landslide and restoration of a site need to be reviewed to assess the location, cause, and impact of the disaster. In addition, on-site investigation is performed with an aim to obtain specific facts about the landslides, including topographic information, time, and type of the incident.

After the site investigation process is completed, the collected data is categorized and saved in the database. Through the risk level assessment table created with a basis on the data, risk level for each site is decided and the analysis and reporting processes are carried out (Figure 1). In this study, the authors make a reasonable selection in regard to the hardware and software to be applied to the system after the site investigation and analysis process. 


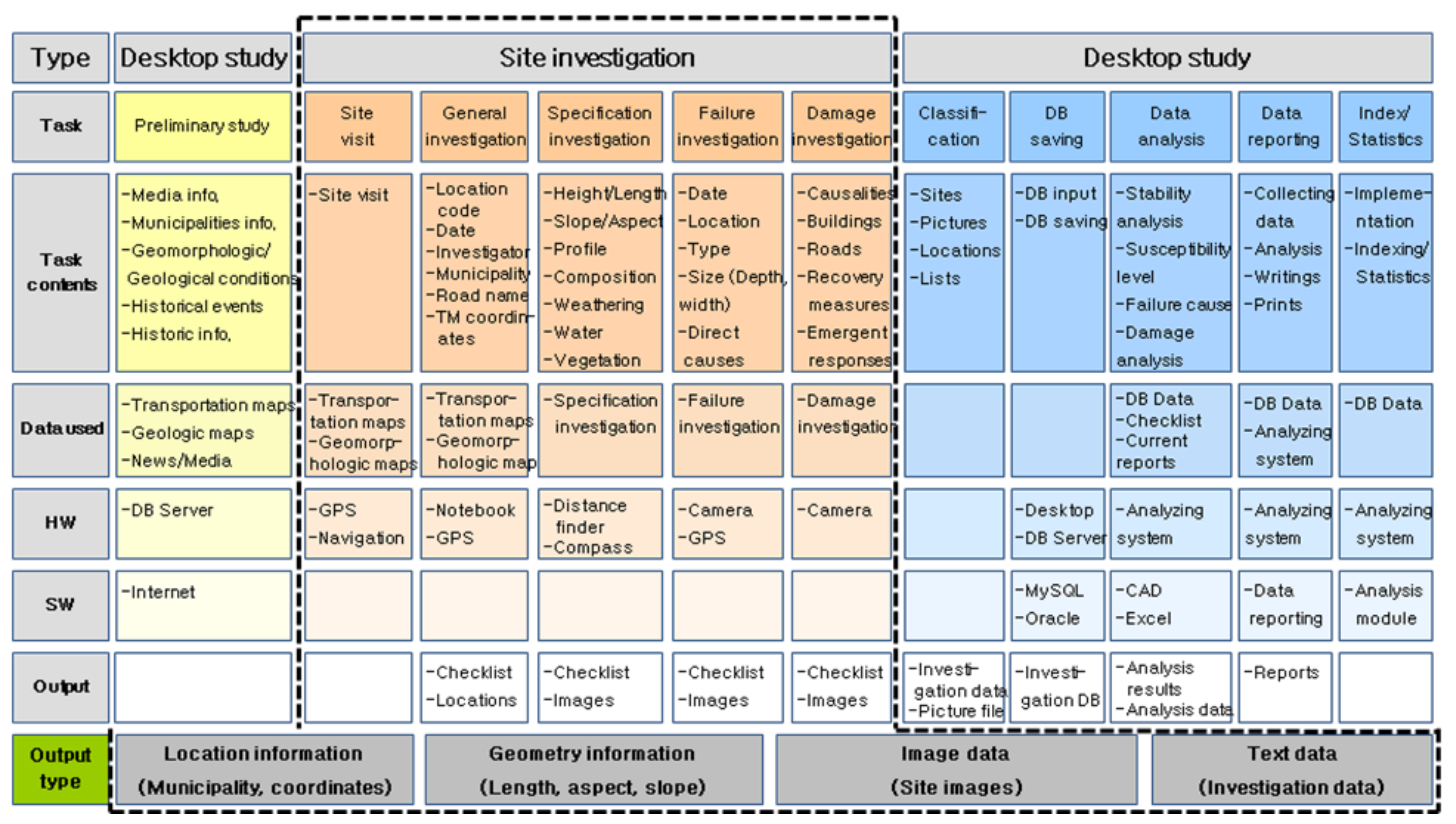

Figure 1. Work flow of the desktop studies and site investigation for steep slopes

\subsection{Information Input System}

The Field Investigation System consists ' Field Information Input System' which helps to add investigated data for steep slope failure areas; ' Field Information Analysis System' which examines acquired data. Figure 2 shows the main window of the Input System. It shows Index Window, Map Display Window, Attribute Window, and Data Input and Analysis Window. The Data Input and Analysis Window have various analysis tabs such as data input, vulnerability evaluation, and stability assessment, etc., and enables to import basic information on steep slopes including the geometry of steep slopes, geological and hydrologic conditions, geologic and geotechnical information, and finally site pictures.

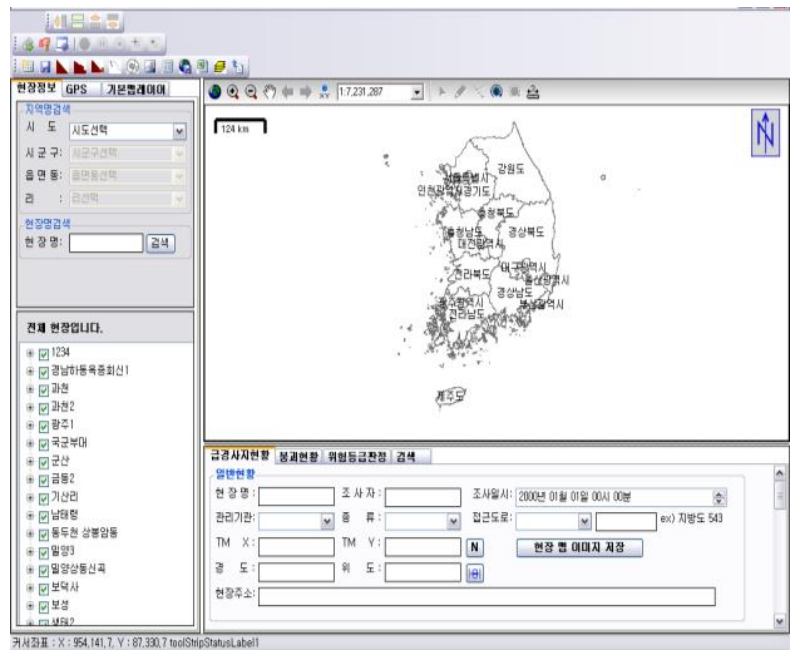

Figure 2. Input screens of the Field Investigation System 
Data for steep slope failure includes failure type and area, depth, length, and height. Generating area information of each polygon from GPS coordinates and digital maps is beneficial especially in case of unstable state of landslide areas where measuring them is quite difficult to calculate. Real time GPS coordinates also enable to determine landslide locations, distance between landslides, tracking of displaced materials, and extent of landslides. Various Digital maps such as geologic, topographical, and index maps can be used to overlap over disaster areas, which easily identify the cause of landslides based on information inherent to them (Figure 3).

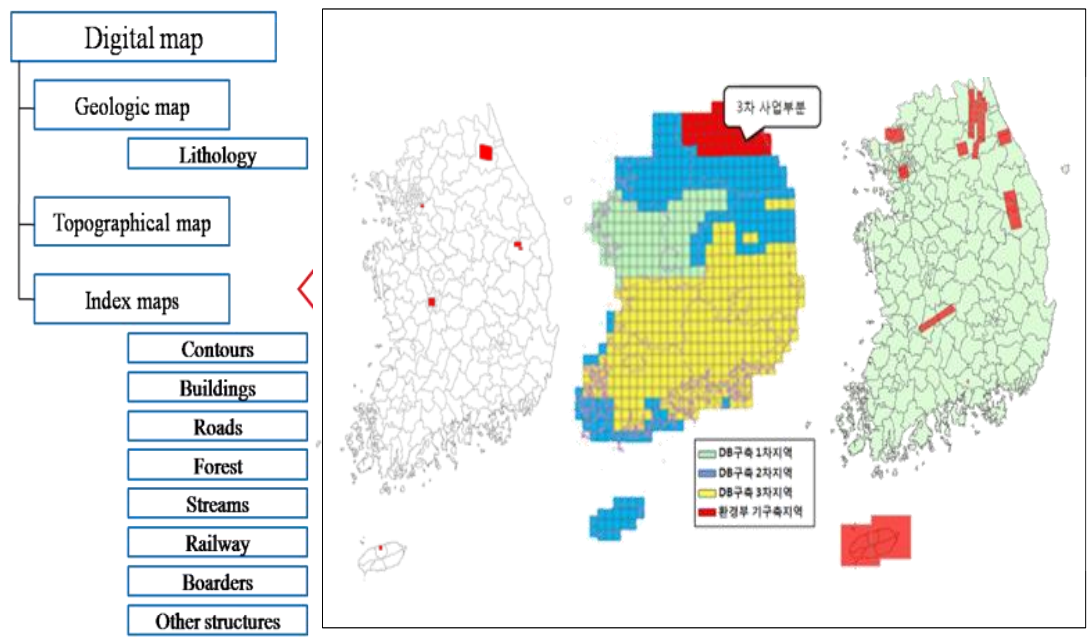

Figure 3. Geologic information using digital map

\subsection{Information Analysis System}

In this system, users can search relevant information, determine the vulnerability level, implement stability analysis, and make the results, all of which are based on the observed data in the field (Figure 4). It also displays field information such as GPS coordinates, distances, spatial attributes (Rock type, vegetation, soil depth) on the base map window, and makes effective steep slope maintenance, cause and impact analysis depending on the different views of field personnel.
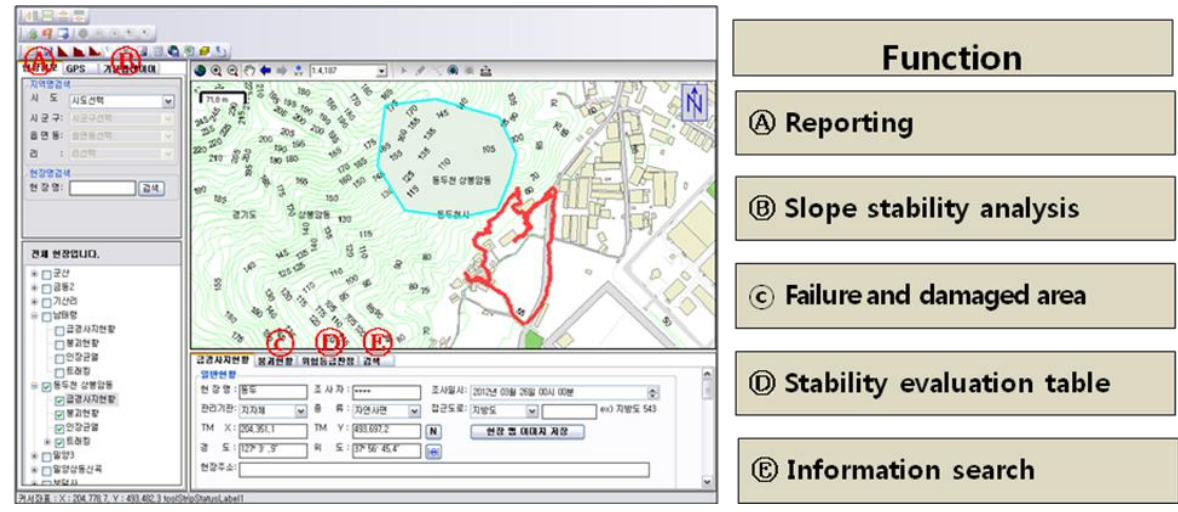

Figure 4. Overview of the analysis system 
The analyzed vulnerability level can be easily determined by the data obtained from site investigation using the Input System of the Field Investigation System. The checklist for vulnerability level proposed by NIDP (2009) is applied to evaluate steep slopes for this system depending on their origin (Soil or Rock slopes). For acquired data during the site investigation, comparing processes to select an appropriate division which related to the evolution of landslide disasters and corresponding values are implemented (Figure 5).

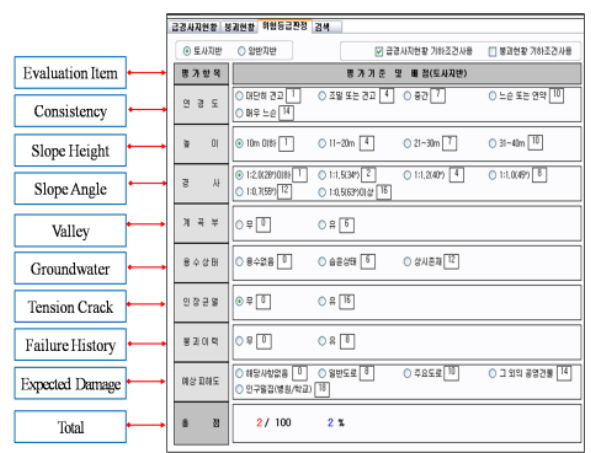

(a) Soil slope

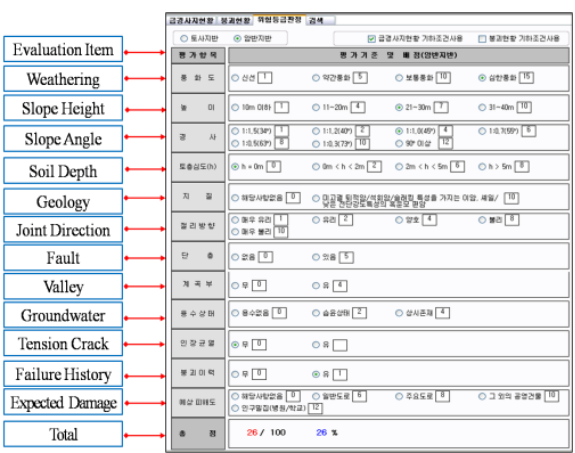

(b) Rock slope

\section{Figure 5. Stability evaluation table}

It also shows the results obtained from analyzing the vulnerability level and input data, which are augmented by the Input System. This enables to manage relevant data in forms of electronic format, which were previously stored as a paper format, and increases the effectiveness and applicability such as searching, reading, printing, and reproducing.

\section{Site Study}

Circumstances around steep slope, its cause of failure, failure region, and risk level were evaluated using the developed Field Investigation System based on the case history of steep slope failure. The investigated steep slope is a natural slope which was failed on July 28th, 2011 due to the torrential rain $(398.0 \mathrm{~mm} / \mathrm{day}, 44.0 \mathrm{~mm} / \mathrm{hr})$. The initial slope failure induced by debris flow and the spreading displaced materials resulted in 4 casualties and destruction of hermitage and houses (Figure 6).

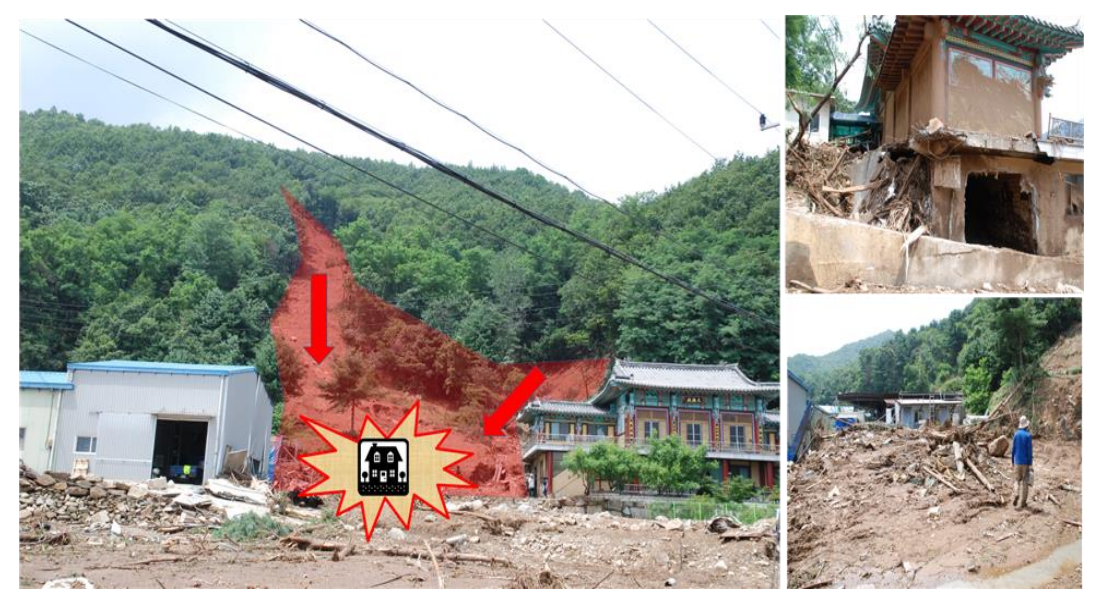

Figure 6. Overview of the study area 
Site investigation using Field Investigation System is conducted as follows:

1) The Field Investigation System is installed to the hazard area and base map and GPS of the system are activated, 2) Location information of hazard area is available by obtaining real-time location coordinates from the connected GPS. 3) From the obtained GPS location information, slope polygon is generated in the map interface of Field Investigation System. 4) For the natural slopes, circumstances and failure situation of steep slope, hazard area estimation can be estimated from the aforementioned GPS tracking information by generating analysis polygon. In other words, site investigator reconstitutes the distribution zone of steep slope in different ways from tracking by performing DEM and by completing surface model using triangular meshes. As a result, slope inclinations with directions and area can be estimated. Typically, the GPS location information is possible if the site investigation is conducted by walking, however, the site of this study was dangerous to assess due to the possibility of additional failure and the spread of displaced materials. Therefore, the generation of slope polygon is done using GPS coordinate information and automaticallygenerated multiple points. Following the process, location of steep slope (GPS coordinates), length $(143.3 \mathrm{~m})$, height $(54.8 \mathrm{~m})$, inclination angle $\left(35^{\circ}\right)$, inclined direction $\left(135^{\circ}\right)$ were automatically calculated and only the drainage condition and site pictures were manually imported. The height and inclination angle of steep slope were calculated from the averages of the information of upper and lower locations of the generated steep slope while the length were obtained from two locations randomly selected or from the direct measurement of distance in the site. 5) Geographic and geological information of steep slope and the hazard area are inputted from the basic maps (layers of topographic map, geological map, structures, and roads, etc.) in the Field Investigation System. From the topographic map of the Field Investigation System, failure initiation location can be clearly identified. By inputting the site information of the failure location to the interface of the Field Investigation System, it was concluded that the failure region had alluvial layer. Considering that the failure region mainly consisted of alluvial zone which was formed from sedimentation during water flows, it is determined that the Field Investigation System successfully predicted the geological characteristics (Figure 7).

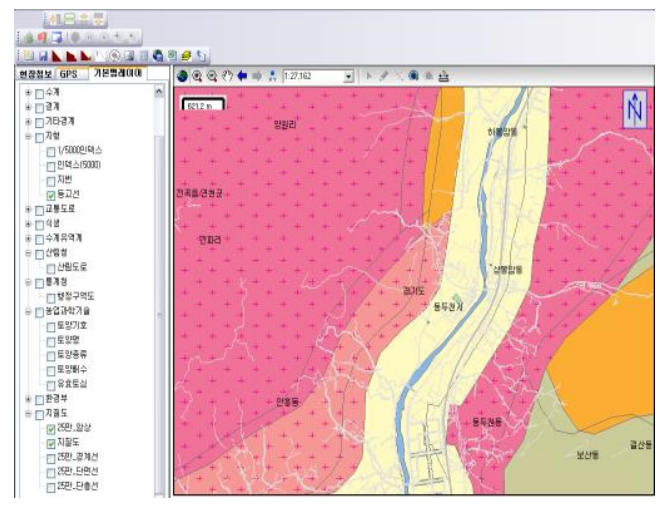

Figure 7. Analysis of the geologic characteristic by using Mobile System 
6) Using the GPS location information obtained by walking or remote-sensing techniques, hazard area (spread area of debris flow) was calculated (Figure 8). Hazard area is obtained from the generation of polygon in digital map and calculation of area information of the polygon. The result of hazard area was calculated as follows: From the failure information of steep slope, the maximum spread distance was $351 \mathrm{~m}$., maximum width was $219 \mathrm{~m}$., total failure area was $22,770 \mathrm{~m}^{2}$. These results well match with the results of ArcGIS from real field measurements. In addition, the distribution of destroyed structures are possible on the layers with the houses and the layers representing roads, therefore, automatically calculation of structure failures (Damaged houses and buildings) was possible.
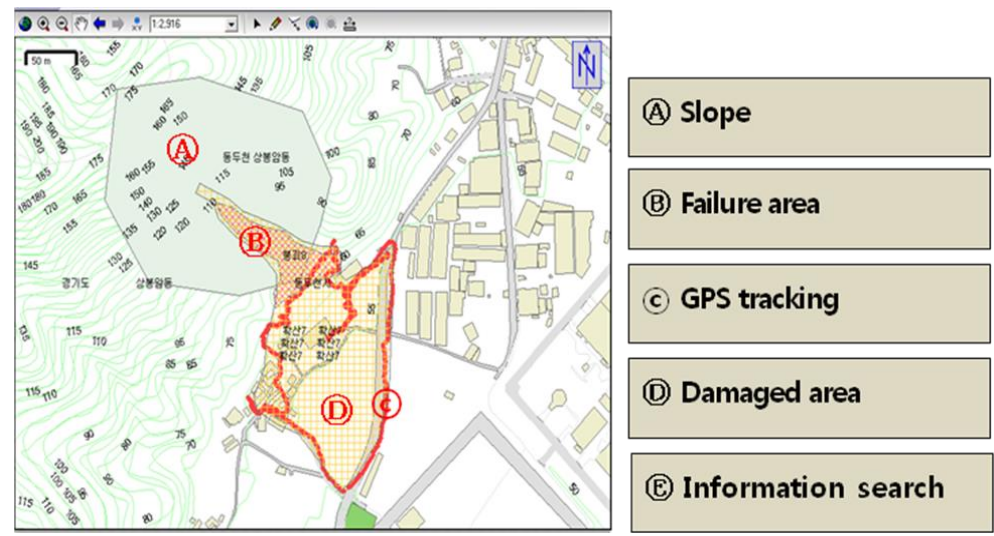

Figure 8. Measurement of damaged area by using Field Investigation System

7) Final step is the generation of the report for site investigation using the Field Investigation System (Fig. 9). The site investigation report automatically consolidates all the pre-mentioned information (situation of failed steep slope, destroyed area, risk level evaluation and so on) and generates a report on ' General Information' and ' Vulnerability Evaluation.'

Therefore, a standardized technical report can be electrically made. From the conventional evaluation method of damaged site, due to its limitation of assess ability of the failed sites, only limited information can be obtained. However, the site investigation using the Field Investigation System enables to providing reasonable user-defined measures of the failure region by consolidating basic inputs of location-wise information as well as the comprehensive site eye-observations. Therefore, it could be a reliable and effective method of examination of failure information. Furthermore, the Field Investigation System is fast in estimation of losses due to slope failure and could be used as a disaster mitigation tool, which selects a optimized countermeasure. 


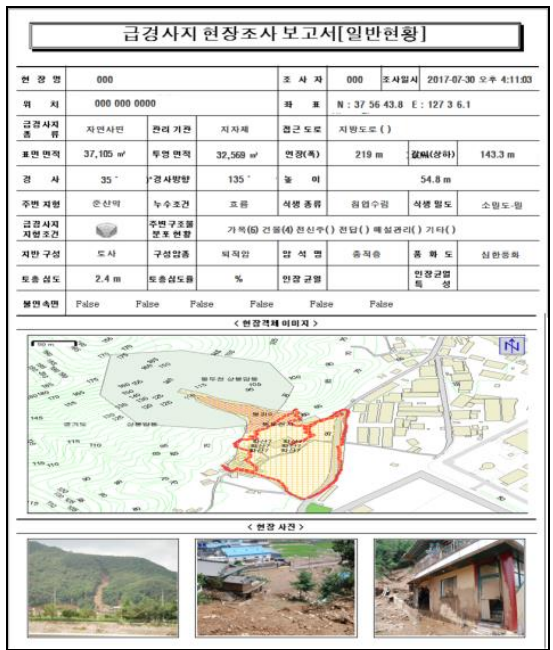

(a) General information

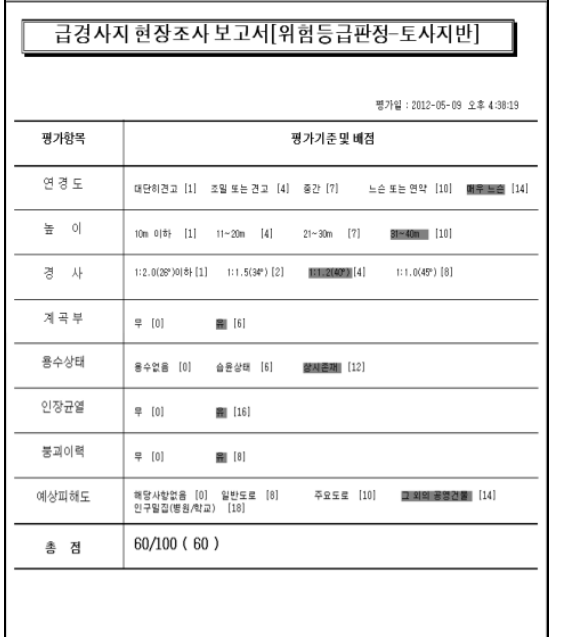

(b) Vulnerability evaluation

\section{Figure 9. Report on Analysis results}

\section{Conclusions}

Despite of increasing steep slope failures due to climate changes, effective management of slope failures is not possible because of the short of specialists in slope investigation and analysis, and lack of effective maintenance based on quantitive measures. Therefore, the development of scientific and technical evaluation system for potentially dangerous slope is required. In this study, for the replacement of the conventional site investigation, which is based on manual recording of information by hand writing near the failure spot, effective Field Investigation System for steep slope is developed.

In this study we proposed two subsystem: 1) Field Information Input System, which enables to write steep slope information automatically; 2) Field Information Analysis System, which evaluates the stability analysis of steep slopes and provides a vulnerability level. All of these are integrated into the Investigation System for steep slopes. The developed Field Investigation System is more effective than the existing methods in terms of time due to the efficient process of consolidating diverse information and to the possible evaluation of quantitive measures of risks. In addition, the Field Investigation System can be also utilized in fields of management, analysis, hazard mitigation of Steep slope.

\section{References}

[1] H. B. Koo, J. H. Lee and S. H. Lee, "Development of techniques for Cut slope using Mobile PC", Journal of Disaster Prevention, vol. 7, no. 4, (2007), pp. 128-136.

[2] J. H. Shim, W. J Choi, J. H. Jung and K. H. Jin, "Investigation Technique of Natural Disaster Using Advanced Technology", journal of korean society of civil engineers, vol. 54, no. 5, (2006), pp. 28-33.

[3] National Institute for Disaster Prevention, "Analyses of Factors affecting Steep-slope Stability and Field Application", (2009), pp. 197.

[4] National Disaster Management Institute, "Developments of the GIS based steep slope collapse determination system (II)", (2012), pp. 140.

[5] NDMS, The National Disaster Management System, Nation-wide Disaster Information Compilation and Database System operated by the National Emergency Management Agency, (2011).

[6] S. W. Park and H. J. Park, "Analysis of Random Properties for JRC using Terrestrial LiDAR", The Journal of Engineering Geology, vol. 21, no. 1, (2011) March, pp. 1-13.

[7] S. H. Lee, "A Study on Measurement of Rock Slope Joint using 3D Image Processing", journal of korean society of civil engineers, vol. 25, no. 2, (2005), pp. 79-84. 
[8] S. I. Jang, I. J. Kang and H. Y. Kang, "Current Survey Method of The Road Cutting Slope Area Using Ntrip Service”, The Korean Society for GeoSpatial Information System, vol. 18, no. 4, (2010), pp. 87-92.
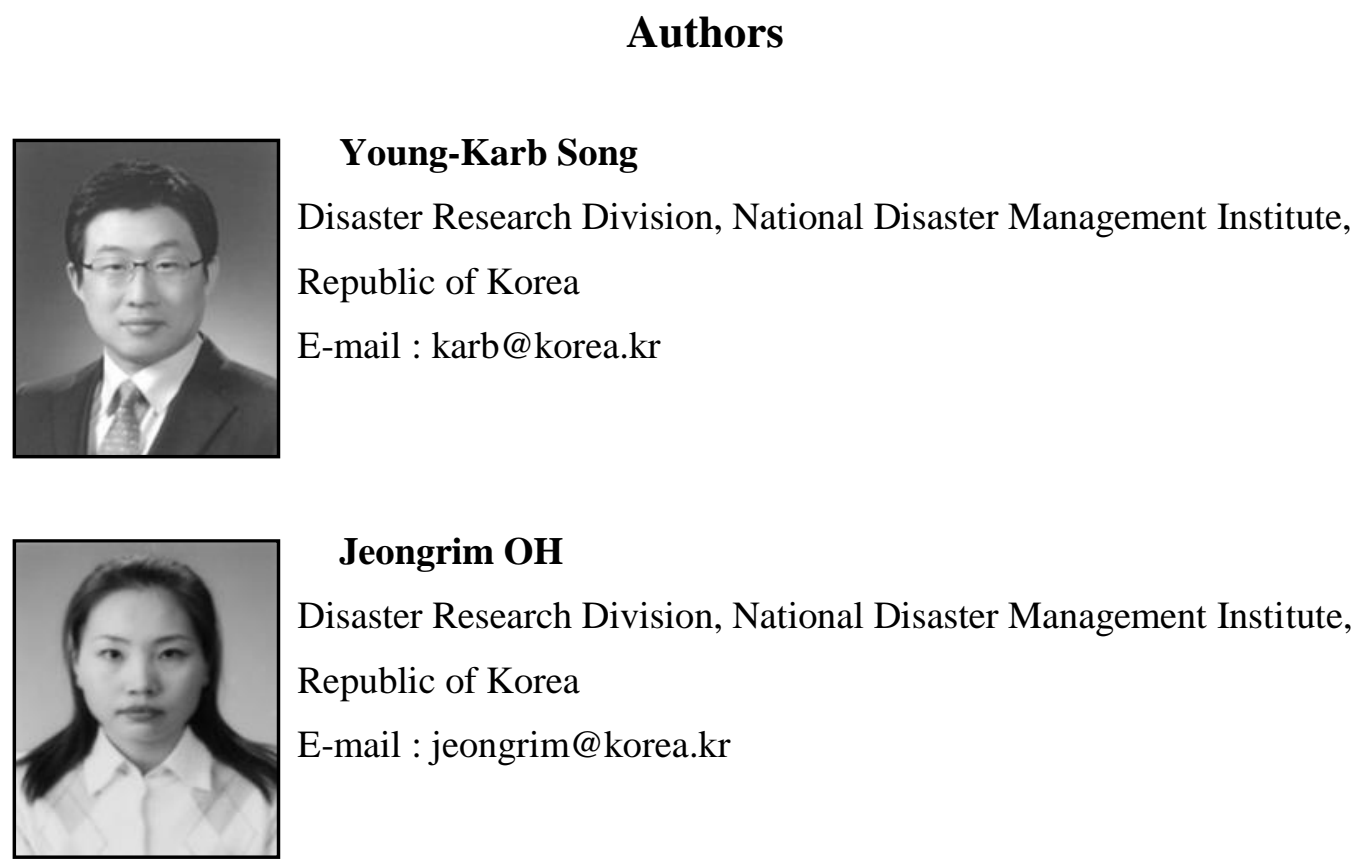

\section{Jeongrim OH}

Disaster Research Division, National Disaster Management Institute, Republic of Korea

E-mail : jeongrim@korea.kr

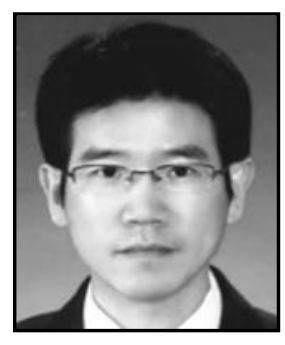

\section{Young-Jin Son}

Disaster Research Division, National Disaster Management Institute, Republic of Korea

E-mail : sonyjin2002@korea.kr

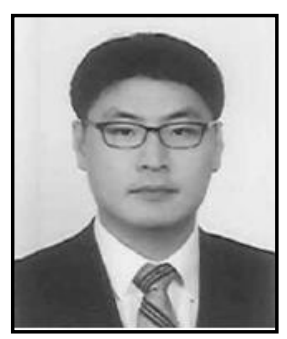

\section{MinSu Jung}

Disaster Research Division, National Disaster Management Institute, Republic of Korea

E-mail : msjung@korea.kr 
International Journal of Disaster Recovery and Business Continuity Vol.4 (2013) 